\title{
Evidence of Asymptomatic Visual Losses after Surgical Repair of Cerebral Aneurysm
}

\author{
Albedy Moreira Bastos ${ }^{1,2}$, Anderson Raiol Rodrigues², Maria Izabel Tentes Côrtes ${ }^{3}$, \\ Eliza Maria da Costa Brito Lacerda², Mônica Gomes Lima', \\ Cláudio Eduardo Corrêa Teixeira ${ }^{2,4,5 *}$ and Luiz Carlos de Lima Silveira ${ }^{1,2}$
}

${ }^{1}$ Instituto de Ciências Biológicas, Universidade Federal do Pará, Belém, Brazil, ${ }^{2}$ Núcleo de Medicina Tropical, Universidade Federal do Pará, Belém, Brazil, ${ }^{3}$ Centro de Ciências da Saúde, Universidade Federal do Amapá, Macapá, Brazil, ${ }^{4}$ Centro de Ciências Biológicas e da Saúde, Universidade da Amazônia, Belém, Brazil, ${ }^{5}$ Centro Universitário do Estado do Pará, Belém, Brazil

OPEN ACCESS

Edited by:

Valerie Purvin,

Midwest Eye Institute, United States

Reviewed by:

Hideki Chuman,

University of Miyazaki, Japan

Mark Paine,

Royal Brisbane and Women's

Hospital, Australia

${ }^{*}$ Correspondence:

Cláudio Eduardo Corrêa Teixeira cecteixeira@pq.cnpq.br

Specialty section:

This article was submitted

to Neuro-Ophthalmology,

a section of the journal

Frontiers in Neurology

Received: 30 August 2016

Accepted: 31 August 2017

Published: 21 September 2017

Citation:

Bastos AM, Rodrigues AR, Côrtes MIT, Lacerda EMCB,

Lima MG, Teixeira CEC and

Silveira LCL (2017) Evidence of

Asymptomatic Visual Losses after

Surgical Repair of Cerebral

Aneurysm.

Front. Neurol. 8:487.

doi: 10.3389/fneur.2017.00487
Deficits in visual acuity, visual field, and oculomotor function are commonly detected after repair of cerebral aneurysms. However, when these deficits are absent, it does not mean that other potential visual deficits also are absent. Here, we report three cases that after complete recover from surgical repair of cerebral aneurysms presented minimal visual acuities of about 20/20 and no visual disturbances. While two of them (Cases 1 and 2) showed visual fields with no relevant central defects, two of them showed relevant impairments in spatial contrast sensitivity (Cases 2 and 3). This evidence supports that after complete recover from surgical repair of hemorrhagic cerebral aneurysms spatial contrast sensitivity can be asymptomatically impaired when visual acuity (Cases 2 and 3) and visual fields (Case 2) are not correlated with symptoms of visual disturbances. Hypothetical explanations and consequences of such evidence are discussed.

Keywords: aneurysm, clipping, visual acuity, visual field, contrast sensitivity function, visual losses

\section{INTRODUCTION}

We describe three cases of patients admitted in the Hospital da Ordem Terceira (Belém, Pará, Brazil) who experienced subarachnoid hemorrhagic events due to rupture of aneurysms. These patients had no prior history of systemic or neuro-ophthalmologic diseases (e.g., diabetes, arterial systemic hypertension, ocular hypertension, cataract, and neurodegenerative diseases such as glaucoma, Parkinson's and Alzheimer's diseases, etc.), neither had experienced any condition that could also affect visual function (e.g., chronic alcoholism, exposition to heavy metals, neurotoxic agents, etc.).

Case 1, a 44-year-old female, was admitted showing headache and meningeal syndrome, grade 2 in the Hunt \& Hess Scale (HHS). Computed tomography showed subarachnoid hemorrhage in the bifurcation between the right posterior communicant and middle cerebral arteries due to a ruptured aneurysm of about $0.8-1.0 \mathrm{~cm}$, grade 1 in the Modified Fisher Scale (MFS). Case 2, a 46-year-old female, was admitted showing headache, meningeal syndrome, and oculomotor nerve palsy, grade 2 in the HHS. Computed tomography showed subarachnoid hemorrhage in the right posterior communicant artery due to a ruptured aneurysm of about $0.7 \mathrm{~cm}$, grade 2 in the MFS. Case 3, a 39-year-old female, was admitted showing headache, dysarthria, left hemiparesis, and meningeal syndrome, grade 2 in the HHS. Computed tomography showed subarachnoid hemorrhage in the bifurcation between the left ophthalmic and middle cerebral arteries due to a ruptured aneurysm 
of about $0.6-1.5 \mathrm{~cm}$, grade 1 in the MFS. Surgical intervention to clip the ruptured aneurysm was successfully performed, and Cases 1,2, and 3 remained hospitalized for 13, 8, and 15 days, respectively. All patients left hospital without any complaints involving visual impairments.

Thereafter, visual health of patients was evaluated by Humphrey automated perimetry, ocular refractometry, retinoscopy, Ishihara pseudoisochromatic plate test, and visual acuity measurement with Snellen Letters. Color vision was normal and visual acuity of both eyes was 20/15, 20/30, and 20/20 for Cases 1, 2, and 3, respectively. No relevant visual central field defects were found in Case 1 (Figure 1) and Case 2 (Figure 2). Case 3 did not perform visual field examination. Then, visual spatial contrast sensitivity function (sCSF) was measured to access possible asymptomatic deficits in visual function undetectable by the abovementioned approaches.

\section{BACKGROUND}

Ruptured or unruptured cerebral aneurysms may cause damages to brain structures and onset of a highly variable visual symptomatology often related to deficits in visual acuity, visual field, and oculomotor function (1-37). After aneurysm repair, the abovementioned visual symptoms might resolve, improve, remain unchanged, or even become worst (38). In addition, visual symptoms absent before surgical interventions can rise just after that (39-43).

The high variability in symptomatology and outcomes after aneurysm repair may be yet higher, mainly because other potential visual deficits diverse from that abovementioned are not detectable using approaches commonly applied to evaluate visual function. For example, Snellen letters and automated perimetry are commonly used to evaluate visual acuity and visual fields, respectively, after aneurysms repair. Such approaches have limitations, since the former only measures visual spatial resolution at high achromatic contrast and spatial frequency, and the latter measures visual spatial detection of the dimmest brightness of targets constant in size and locations. However, in real scenes, objects show dynamic contrast levels with their surroundings and diverse spatial frequencies, depending on how light intensity varies in space and time $(44,45)$. Thus, additional

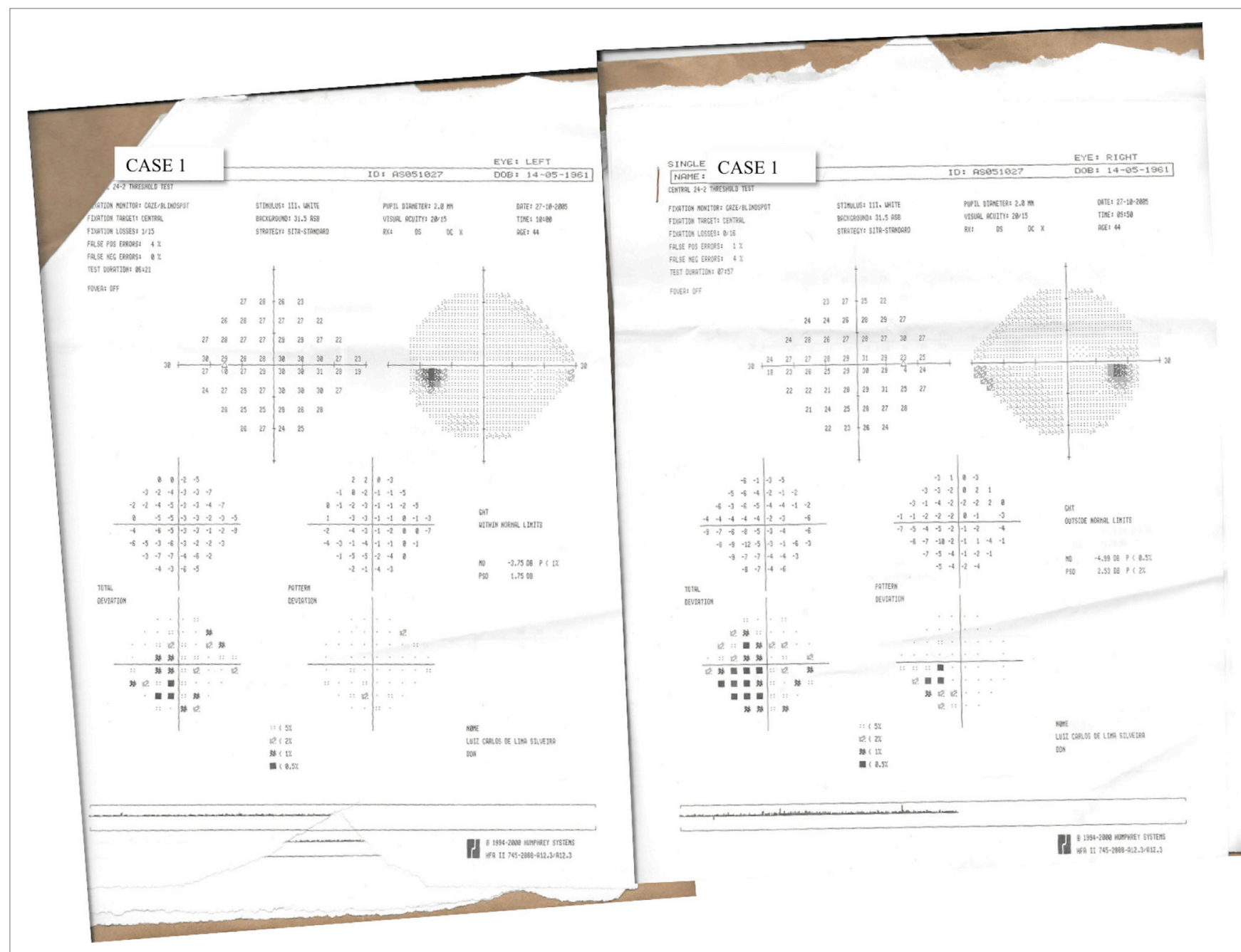

FIGURE 1 | Results of 24-2 threshold test of Humphrey automated perimetry performed by Case 1. 


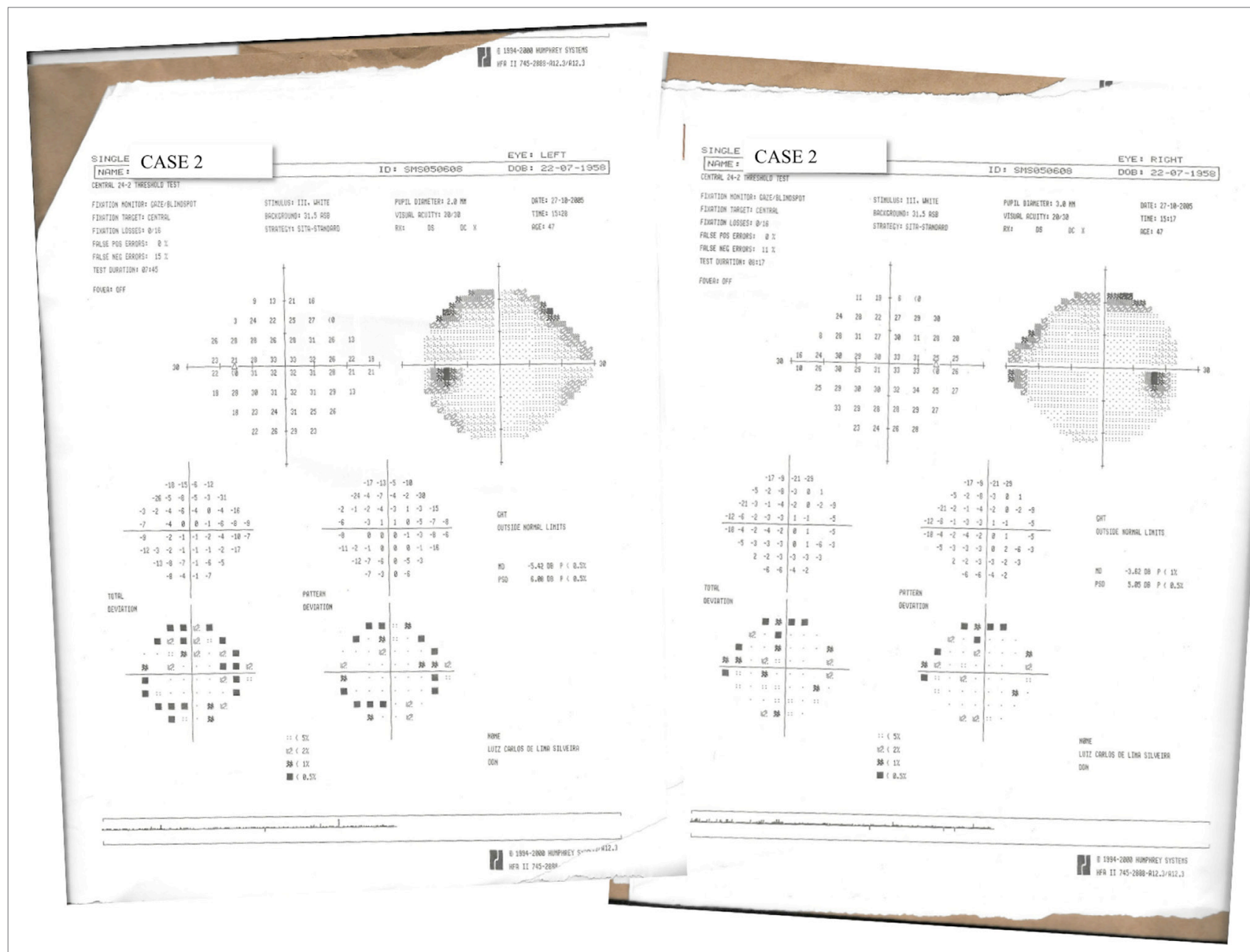

FIGURE 2 | Results of 24-2 threshold test of Humphrey automated perimetry performed by Case 2.

measurement of sCSF of such patients should contribute to a more accurate measure of their visual health after aneurysm repair (46).

\section{DISCUSSION}

Visual spatial contrast sensitivity test was written in $\mathrm{C}++$. An Annihilator 2 graphic card (Creative Labs, OK, USA) driven by a Pentium VI personal computer connected to a gammacorrected 19-inch monitor (Sony Trinitron Multiscan G420, $1,024 \times 768$ pixels spatial resolution and $120 \mathrm{~Hz}$ refresh rate) was used to perform sCSF measurements. The luminance $\left(\mathrm{cd} \mathrm{m} \mathrm{m}^{-2}\right.$ ) and chromaticity (CIE 1931; Y, x, y) of the monitors were measured with a CS-100A chromameter with a $1^{\circ}$ measurement angle (Konica Minolta, Mahwah, NJ, USA). In addition, a dithering technique was used to achieve a gray level resolution of 10 bits in the generation of luminance sinusoidal patterns for the visual threshold measurements (47-49). Visual stimuli consisted of stationary, black-and-white (CIE 1976; $\left.u^{\prime}=0.182, v^{\prime}=0.474\right)$ vertical sine-wave gratings with a mean luminance of $43.5 \mathrm{~cd} \mathrm{~m}^{-2}$ at 10 spatial frequencies [0.2, 0.5, $0.8,1,2,4,8,10,15$, and 20 cycles/degree (cpd)]. The stimuli were placed $3 \mathrm{~m}$ from the subject and measured $6.5^{\circ} \times 5^{\circ}$ of visual angle. Contrast sensitivity to luminance spatial gratings was measured using the staircase procedure (50). The results of contrast sensitivity are expressed in terms of logarithmic units of Michelson contrast. All psychophysical measurements were performed monocularly.

This study followed the guidelines of the Helsinki Declaration and was approved by the Ethics Committee for Research with Humans of the Tropical Medicine Nucleus, Federal University of Pará, Resolution 196/96-CNS/MS (Protocol no. 036/2005$\mathrm{CEP} / \mathrm{NMT}$ ). All patients included in the study gave written and informed consent to participate in this work.

Visual sCSF was measured $2 \times$ using foveal vision, being the first measurement used only to allow understanding about test procedures. In Figure 3, sCSF of each patient is compared with $95 \%$ confidence interval of the mean sCSF of 27 healthy subjects ( $51 \pm 6$ years old), who performed $3 \times$ each the visual test, just with the right eye. Figure 3 shows that Case 1 (visual acuity 


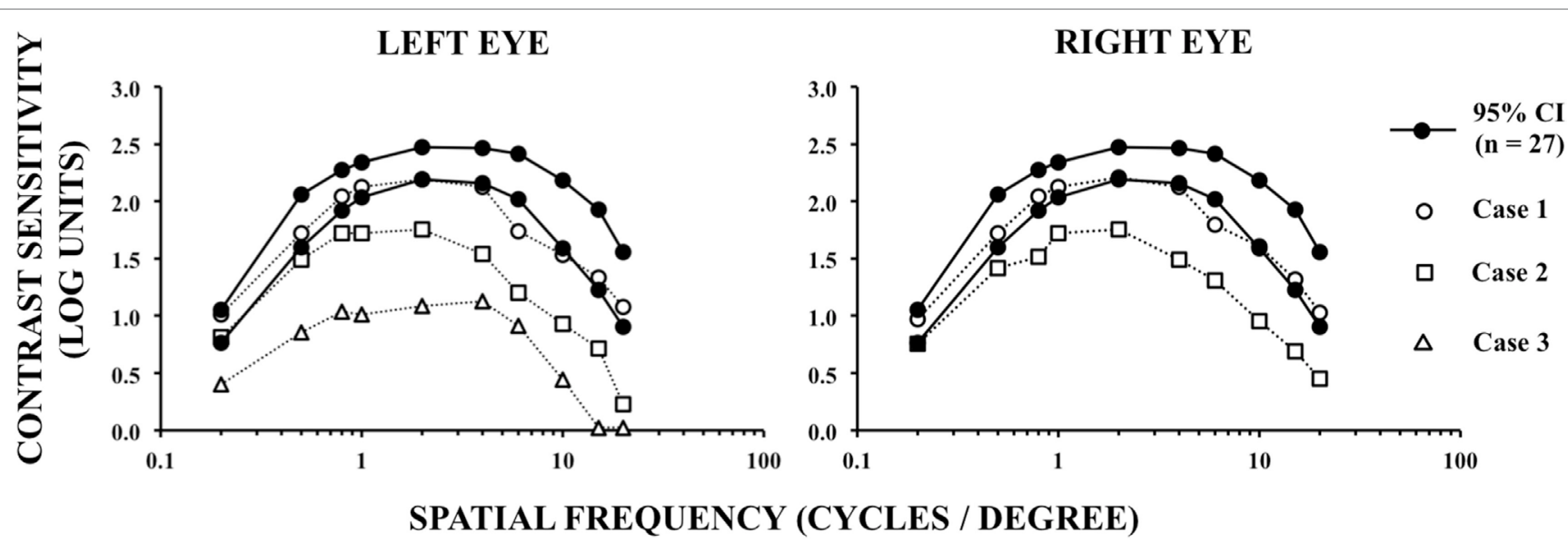

FIGURE 3 | Spatial contrast sensitivity function measured as a function of the spatial frequencies of achromatic visual stimuli.

20/15) presented a normal pattern for sCSF, with cutoff at $20 \mathrm{cpd}$; for both eyes Case 2 (visual acuity 20/30) presented a decrease in sCSF for intermediary and high spatial frequencies, with cutoff at $20 \mathrm{cpd}$; and although Case 3 (visual acuity 20/20) had measured sCSF only with the left eye, it presented a decrease in contrast sensitivity for all spatial frequencies tested, with cutoff at $15 \mathrm{cpd}$. To the best of our knowledge, this is the first report of a patient (Case 2) showing visual acuity and visual field with no relevant foveal alterations concurrent with altered foveal sCSF after repair of hemorrhagic aneurysm. In general, alterations of sCSF are related to other diverse disorders that can affect the visual neural pathway $(46,51)$.

\section{CONCLUDING REMARKS}

Contrast sensitivity losses shown in this case report might be explained by neural damage due to subarachnoid hemorrhage, increased intracranial pressure, the surgical clipping, or all of it. Therefore, the absence of contrast sensitivity losses in Case 1 and the presence of contrast sensitivity losses in Case 2 could be explained by a more extensive neural damage in the latter, damage that was not fully detected by perimetry. For example, since both Cases 1 and 2 underwent hemorrhagic events in the right posterior communicant artery, and considering that retina contralateral fibers feed thalamic-cortical visual pathways in higher number than ipsilateral fibers, the normal sCSF in Case 1 could be explained by a damage limited to a smaller amount of ipsilateral (right eye) and contralateral (left eye) fibers than that damaged in Case 2.

On the other hand, sCSF is maximal at central visual field and then decreases with eccentricity for all azimuths $(52,53)$. Therefore, it is expected that the decrease in visual sensitivity at large eccentricities of visual field, as that observed in Case 2, should be poorly correlated with central sCSF impairment observed in Case 2. Thus, sCSF impairment observed in Case 2 should also be analyzed considering that specific visual field defects do not always indicate damages at specific and correlated brain locations $(54,55)$. Clatworthy et al. (56) have already demonstrated that sCSF may be not affected even when central visual field defects are present in patients showing homonymous hemianopia sparing foveal vision after stroke.

However, the reasons why there is a change in sCSF in Case 2 can only be inferred out of speculation by analyzing the pattern of sCSF curve. When the curve peak is shifted downward, there is probably a loss in the mechanism which increases contrast sensitivity in the mid frequencies range. Although some authors earlier have described this mechanism as of inhibitory nature and related to neural mechanism that produces the Mach bands $(57,58)$, the current literature still lacks evidence about this issue. Thus, in cases where sCSF peak is depressed, all damages to retina, optic nerve, or visual pathways are candidates to be associated with this shift downward. Thus, while the shift downward of sCSF curve measured with the left eye in Case 3 might be related to damage in neural tissue near the left ophthalmic artery, the reason of the shift downward of sCSF curve in Case 2 is not easy to explain. Optical coherence tomography and visual evoked potentials datasets should be interesting to analyze in such cases, ideally before and after aneurysm rupture/repair. However, unfortunately, it was not possible to perform more evaluations in the present cases than that already described, since they went back to their hometown after recover.

Finally, only future studies will confirm and clarify this issue that is important to patients, ophthalmologists, and neurosurgeons, since detection of visual losses in these cases, yet asymptomatic, can support the evidence of possible neurological and/ or circulatory worse prognosis after surgical repair of aneurysms $(8,59)$. It is already recommendable that subjects who had undergone clipping surgery of intracranial aneurysms have evaluated their visual performance in adequate periods $(17,19,30,60)$. Unfortunately, approaches commonly used in ophthalmologic clinics to evaluate visual health in such cases include visual acuity and visual field measurements, and do not include sCSF measurements. 


\section{ETHICS STATEMENT}

This study followed the guidelines of the Helsinki Declaration and was approved by the Ethics Committee for Research with Humans of the Tropical Medicine Nucleus, Federal University of Pará, Resolution 196/96-CNS/MS (Protocol no. 036/2005-CEP/ NMT). Patients voluntarily signed an informed consent to participate in this work.

\section{AUTHOR CONTRIBUTIONS}

$\mathrm{AB}, \mathrm{AR}, \mathrm{CT}$, and LS contributed to the study conception and design. AB, AR, MC, EL, ML, CT, and LS contributed to acquisition, analysis and interpretation of data, and drafting of this manuscript with regard to important intellectual content.

\section{REFERENCES}

1. Norwood EG, Kline LB, Chandra-Sekar B, Harsh GR III. Aneurysmal compression of the anterior visual pathways. Neurologia (1986) 36:1035-41. doi:10.1212/WNL.36.8.1035

2. Feely M, Kapoor S. Third nerve palsy due to posterior communicating artery aneurysm: the importance of early surgery. J Neurol Neurosurg Psychiatry (1987) 50(8):1051-2. doi:10.1136/jnnp.50.8.1051

3. Fujiwara S, Fujii K, Nishio S, Matsushima T, Fukui M. Oculomotor nerve palsy in patients with cerebral aneurysms. Neurosurg Rev (1989) 12(2):123-32. doi:10.1007/BF01741485

4. Kyriakides T, Aziz TZ, Torrens MJ. Postoperative recovery of third nerve palsy due to posterior communicating aneurysms. Br J Neurosurg (1989) 3(1):109-11. doi:10.3109/02688698909001032

5. Ruben S, Afshar F. Visual failure following subarachnoid haemorrhage from rupture of an anterior communicating artery aneurysm. J Neurol Neurosurg Psychiatry (1991) 54(11):1017-8. doi:10.1136/jnnp.54.11.1017

6. Giombini S, Ferraresi S, Pluchino F. Reversal of oculomotor disorders after intracranial aneurysm surgery. Acta Neurochir (Wien) (1991) 112(1-2):19-24. doi:10.1007/BF01402449

7. Date I, Akiota T, Ohmoto T. Penetration of the optic chiasm by a ruptured anterior communicating artery aneurysm: case report. J Neurosurg (1997) 87:324-6. doi:10.3171/jns.1997.87.2.0324

8. Date I, Asari S, Ohmoto T. Cerebral aneurysms causing visual symptoms: their features and surgical outcome. Clin Neurol Neurosurg (1998) 100:259-67. doi:10.1016/S0303-8467(98)00047-X

9. Fujita A, Tamaki N, Yasuo K, Nagashima T, Ehara K. Complete penetration of the optic chiasm by an unruptured aneurysm of the ophthalmic segment: case report. Surg Neurol (2002) 57:130-4. doi:10.1016/S0090-3019(01)00695-4

10. Hall JK, Jacobs DA, Movsas T, Galetta SL. Fourth nerve palsy, homonymous hemianopia, and hemisensory deficit caused by a proximal posterior cerebral artery aneurysm. J Neuroophthalmol (2002) 22(2):95-8. doi:10.1097/00041327-200206000-00006

11. Nishino A, Sakuray Y, Arai H, Nishimura S, Suzuki S, Uenohara H. Clinical manifestations, character of aneurysms, and surgical results for unruptured cerebral aneurysms presenting with ophthalmic symptoms. Acta Neurochir (2002) 82:47-9. doi:10.1007/978-3-7091-6736-6_9

12. Pico F, Biousse V, Chapot R, Bousser MG. Aneurysm of the anterior cerebral artery disclosed by unique hemianopic scotoma. Rev Neurol (Paris) (2002) 158(3):347-50.

13. Yanaka K, Matsumaru Y, Mashiko R, Hyodo A, Sugimoto K, Nose T. Small unruptured cerebral aneurysms presenting with oculomotor nerve palsy. Neurosurgery (2003) 52(3):553-7. doi:10.1227/01.NEU.0000047816.02757.39

14. Craenen G, Brown SM, Freedman KA, Windisch TR, Corona J. Rapid, painless unilateral vision loss in a 37-year-old healthy woman. Surv Ophthalmol (2004) 49(3):343-8. doi:10.1016/j.survophthal.2004.02.012

15. Dimopoulos VG, Fountas KN, Feltes CH, Robinson JS, Grigorian AA. Literature review regarding the methodology of assessing third nerve paresis

\section{ACKNOWLEDGMENTS}

The authors thank patients for their participation. We dedicate this work to Prof. Luiz Carlos Silveira (1953-2016).

\section{FUNDING}

This work was supported by CNPq-PRONEX/FAPESPA (grant number 2268); CNPq-PRONEX/FAPESPA (grant number 316799/2009); CNPq (grant numbers 620037/2008-3, 476744/ 2009-1); CAPES-PROCAD (grant number 182/2007); and FINEP/UFPA/FADESP (grant number 1723) (IBN Net). EL, ML, and CT received, respectively, CNPq, CAPES-PROF, and CAPESPROCAD studentships. LS was a CNPq research fellow.

associated with non-ruptured posterior communicating artery aneurysms Neurosurg Rev (2005) 28(4):256-60. doi:10.1007/s10143-005-0393-6

16. Chen PR, Amin-Hanjani S, Albuquerque FC, McDougall C, Zabramski JM, Spetzler RF. Outcome of oculomotor nerve palsy from posterior communicating artery aneurysms: comparison of clipping and coiling. Neurosurgery (2006) 58(6):1040-6. doi:10.1227/01.NEU.0000215853.95187.5E

17. Chong CT, Chin KJ, Yip LW, Singh K. Case series: monocular visual loss associated with subarachnoid hemorrhage secondary to ruptured intracranial aneurysms. Can J Anaesth (2006) 53:684-9. doi:10.1007/BF03021627

18. Claes C, Milea D, Bodaghi B, Tran TH, LeHoang P, Blanc R. Acute retrobulbar optic neuropathy due to rupture of an anterior communicating artery aneurysm. Acta Ophthalmol Scand (2006) 84(1):145-6. doi:10.1111/j.1600-0420.2005.00545.x

19. Tawk RG, Villalobos HJ, Levy EI, Hopkins LN. Surgical decompression and coil removal for the recovery of vision after coiling and proximal occlusion of a clinoidal segment aneurysm: technical case report. Neurosurgery (2006) 58:1217-8. doi:10.1227/01.NEU.0000215995.09860.0A

20. Heran NS, Song JK, Kupersmith MJ, Niimi Y, Namba K, Langer DJ, et al. Large ophthalmic segment aneurysms with anterior optic pathway compression: assessment of anatomical and visual outcomes after endosaccular coil therapy. J Neurosurg (2007) 106(6):968-75. doi:10.3171/jns.2007.106.6.968

21. Joo SP, Kim TS. Splitting of the optic nerve associated with ruptured anterior communicating artery aneurysm - case report. Neurol Med Chir (Tokio) (2007) 47:501-2. doi:10.2176/nmc.47.501

22. Harsan H, Eka JW, Julius J. Decrease of visual fields due to re-growth of a big aneurysm after coiling. A case report. Interv Neuroradiol (2008) 14(2):99-101. doi:10.1177/15910199080140S218

23. van Rooij WJ, Sluzewski M, Beute GN. Internal carotid bifurcation aneurysms: frequency, angiographic anatomy and results of coiling in 50 aneurysms. Neuroradiology (2008) 50(7):583-7. doi:10.1007/s00234-008-0375-9

24. Hagihara N, Abe T, Yoshioka F, Watanabe M, Tabuchi K. Photophobia as the visual manifestation of chiasmal compression by unruptured anterior communicating artery aneurysm. Neurol Med Chir (Tokio) (2009) 49:159-61. doi: $10.2176 / \mathrm{nmc} .49 .159$

25. Mendez Roberts A, Grimes AL. Enlargement of internal carotid artery aneurysm presenting with severe visual sequela: a case report and anatomy review. Optometry (2009) 80(2):76-82. doi:10.1016/j.optm.2008.05.009

26. de Oliveira JG, Borba LA, Rassi-Neto A, de Moura SM, Sanchez-Júnior SL, Rassi MS, et al. Intracranial aneurysms presenting with mass effect over the anterior optic pathways: neurosurgical management and outcomes. Neurosurg Focus (2009) 26(5):E3. doi:10.3171/2009.3.FOCUS0924

27. Park JH, Park SK, Kim TH, Shin JJ, Shin HS, Hwang HS. Anterior communicating artery aneurysm related to visual symptoms. J Korean Neurosurg Soc (2009) 46:232-8. doi:10.3340/jkns.2009.46.3.232

28. Nam KH, Hamm IS, Kang DH, Park J, Kim YS. Risk of shunt dependent hydrocephalus after treatment of ruptured intracranial aneurysms: surgical clipping versus endovascular coiling according to fisher grading system. J Korean Neurosurg Soc (2010) 48(4):313-8. doi:10.3340/jkns.2010.48.4.313 
29. Yerramneni VK, Chandra PS, Kasliwal MK, Sinha S, Suri A, Gupta A, et al. Recovery of oculomotor nerve palsy following surgical clipping of posterior communicating artery aneurysms. Neurol India (2010) 58(1):103-5. doi:10.4103/0028-3886.60413

30. Attia M, Cohen JE, Shapira OM, Eimerl D, Gomori MJ, Dotan S, et al. Visual failure and recovery after thrombosis of a giant carotid ophthalmic aneurysm following vascular bypass and carotid artery ligation. J Clin Neurosci (2011) 18:152-4. doi:10.1016/j.jocn.2010.06.017

31. Bhat DI, Sampath S. Anterior communicating artery aneurysm presenting as monocular blindness. Br J Neurosurg (2011) 25(5):644-6. doi:10.3109/ 02688697.2010.544782

32. Dehdashti AR, Le Roux A, Bacigaluppi S, Wallace MC. Long-term visual outcome and aneurysm obliteration rate for very large and giant ophthalmic segment aneurysms: assessment of surgical treatment. Acta Neurochir (Wien) (2012) 154(1):43-52. doi:10.1007/s00701-011-1167-2

33. Nanda A, Javalkar V. Microneurosurgical management of ophthalmic segment of the internal carotid artery aneurysms: single-surgeon operative experience from Louisiana State University, Shreveport. Neurosurgery (2011) 68(2):355-71. doi:10.1227/NEU.0b013e3182039819

34. Panagiotopoulos V, Ladd SC, Gizewski E, Asgari S, Sandalcioglu EI, Forsting M, et al. Recovery of ophthalmoplegia after endovascular treatment of intracranial aneurysms. AJNR Am J Neuroradiol (2011) 32(2):276-82. doi:10.3174/ ajnr.A2281

35. Güresir E, Schuss P, Seifert V, Vatter H. Oculomotor nerve palsy by posterior communicating artery aneurysms: influence of surgical strategy on recovery. J Neurosurg (2012) 117(5):904-10. doi:10.3171/2012.8.JNS111239

36. García Carreira MC, Cánovas Vergé D, Marco Igual M, Hervàs Pujol M. Bilateral supraclinoid aneurysms associated with progressive visual impairment. Neurologia (2013) 28(2):119-20. doi:10.1016/j.nrl.2011.07.002

37. MattinglyT, Kole MK, Nicolle D, Boulton M, PelzD, Lownie SP. Visual outcomes for surgical treatment of large and giant carotid ophthalmic segment aneurysms: a case series utilizing retrograde suction decompression (the "Dallas technique"). J Neurosurg (2013) 118(5):937-46. doi:10.3171/2013.2.JNS12735

38. Schuss P, Güresir E, Berkefeld J, Seifert V, Vatter H. Influence of surgical or endovascular treatment on visual symptoms caused by intracranial aneurysms: single-center series and systematic review. J Neurosurg (2011) 115(4):694-9. doi:10.3171/2011.5.JNS101983

39. Kang S, Yang Y, Kim T, Kim J. Sudden unilateral blindness after intracranial aneurysm surgery. Acta Neurochir (Wien) (1997) 139:221-6. doi:10.1007/BF01844755

40. Pickett GE, Laitt RD, Herwadkar A, Hughes DG. Visual pathway compromise after hydrocoil treatment of large ophthalmic aneurysms. Neurosurgery (2007) 61(4):E873-4. doi:10.1227/01.NEU.0000298918.55119.7C

41. Schmidt GW, Oster SF, Golnik KC, Tumiala’n LM, Biousse V, Turbin R, et al. Isolated progressive visual loss after coiling of paraclinoid aneurysms. AJNR Am J Neuroradiol (2007) 28:1882-9. doi:10.3174/ajnr.A0690

42. Fulkerson DH, Horner TG, Payner TD, Leipzig TJ, Scott JA, DeNardo AJ, et al. Results, outcomes, and follow-up of remnants in the treatment of ophthalmic aneurysms: a 16-year experience of a combined neurosurgical and endovascular team. Neurosurgery (2009) 64(2):218-30. doi:10.1227/01. NEU.0000337127.73667.80

43. Killer M, Baltsavias G, Huemer M, Richling B. Visual worsening after incomplete coiling of a small asymptomatic aneurysm: case report and review of the literature. Minim Invasive Neurosurg (2009) 52(1):39-43. doi:10.1055/ s-0028-1104565
44. Mante V, Frazor RA, Bonin V, Geisler WS, Carandini M. Independence of luminance and contrast in natural scenes and in the early visual system. Nat Neurosci (2005) 8(12):1690-7. doi:10.1038/nn1556

45. Frazor RA, Geisler WS. Local luminance and contrast in natural images. Vis Res (2006) 46(10):1585-98. doi:10.1016/j.visres.2005.06.038

46. Arden GB. The importance of measuring contrast sensitivity in cases of visual disturbance. Br J Ophthalmol (1978) 62:198-209. doi:10.1136/bjo.62.4.198

47. Cowan WB. An inexpensive scheme for calibration of a color monitor in terms of CIE standard coordinates. Comput Graph (1983) 17:315-21. doi:10.1145/964967.801163

48. Bach M, Meigen T, Strasburger H. Raster-scan cathode-ray tubes for vision research - limits of resolution in space, time and intensity, and some solutions. Spat Vis (1997) 10:403-14. doi:10.1163/156856897X00311

49. Hearn D, Baker MP. Computer Graphics - C Version. 2nd ed. Englewood Cliffs, NJ: Prentice Hall Press (1997).

50. Treutwein B. Adaptive psychophysical procedures. Vis Res (1995) 35(17):2503-22. doi:10.1016/0042-6989(95)00016-X

51. Jackson GR, Owsley C. Visual dysfunction, neurodegenerative diseases, and aging. Neurol Clin (2003) 21:709-28. doi:10.1016/S0733-8619(02)00107-X

52. RijsdijkJP,KroonJN,vanderWildtGJ. Contrastsensitivityasafunction ofposition on the retina. Vis Res (1980) 20(3):235-41. doi:10.1016/0042-6989(80)90108-X

53. Regan D, Beverley KI. Visual fields described by contrast sensitivity, by acuity, and by relative sensitivity to different orientations. Invest Ophthalmol Vis Sci (1983) 24:754-9.

54. Zhang X, Kedar S, Lynn MJ, Newman NJ, Biousse V. Homonymous hemianopias: clinical-anatomic correlations in 904 cases. Neurology (2006) 28(66):906-10. doi:10.1212/01.wnl.0000203913.12088.93

55. Kedar S, Ghate D, Corbet JJ. Visual fields in neuro-ophthalmology. Indian J Ophthalmol (2011) 59(2):103-9. doi:10.4103/0301-4738.77013

56. Clatworthy PL, Warburton EA, Tolhurst DJ, Baron JC. Visual contrast sensitivity deficits in 'normal' visual field of patients with homonymous visual field defects due to stroke: a pilot study. Cerebrovasc Dis (2013) 36(5-6):329-35. doi:10.1159/000354810

57. Ratliff F. Mach Bands: Quantitative Studies on Neural Networks in the Retina. San Francisco, CA: Holden-Day (1965).

58. Kelly DH, Magnuski HS. Pattern detection and two-dimensional Fourier transform:circulartargets. VisRes(1975)15:911-5.doi:10.1016/0042-6989(75)90230-8

59. Vargas ME, Kupersmith MJ, Setton A, Nelson K, Berenstein A. Endovascular treatment of giant aneurysms which cause visual loss. Ophthalmology (1994) 101:1091-8. doi:10.1016/S0161-6420(94)31213-9

60. Khan S, Leung E, Jay WM. Stroke and visual rehabilitation. Top Stroke Rehabil (2008) 15:27-36. doi:10.1310/tsr1501-27

Conflict of Interest Statement: The authors declare that the research was conducted in the absence of any commercial or financial relationships that could be construed as a potential conflict of interest.

Copyright (c) 2017 Bastos, Rodrigues, Côrtes, Lacerda, Lima, Teixeira and Silveira. This is an open-access article distributed under the terms of the Creative Commons Attribution License (CC BY). The use, distribution or reproduction in other forums is permitted, provided the original author(s) or licensor are credited and that the original publication in this journal is cited, in accordance with accepted academic practice. No use, distribution or reproduction is permitted which does not comply with these terms. 